\title{
Primary localized rectal/pararectal gastrointestinal stromal tumors: results of surgical and multimodal therapy from the French Sarcoma group
}

Thanh-Khoa Huynh ${ }^{1,15^{*}}$, Pierre Meeus ${ }^{2}$, Philippe Cassier ${ }^{3}$, Olivier Bouché ${ }^{4}$, Sophie Lardière-Deguelte ${ }^{5}$, Antoine Adenis ${ }^{6}$, Thierry André ${ }^{7}$, Julien Mancini ${ }^{8}$, Olivier Collard ${ }^{9}$, Michael Montemurro ${ }^{10}$, Emmanuelle Bompas ${ }^{11}$, Maria Rios ${ }^{12}$, Nicolas Isambert ${ }^{13}$, Didier Cupissol ${ }^{14}$, Jean-Yves Blay ${ }^{3}$ and Florence Duffaud ${ }^{1}$

\begin{abstract}
Background: Rectal and pararectal gastrointestinal stromal tumors (GISTs) are rare. The optimal management strategy for primary localized GISTs remains poorly defined.

Methods: We conducted a retrospective analysis of 41 patients with localized rectal or pararectal GISTs treated between 1991 and 2011 in 13 French Sarcoma Group centers.

Results: Of 12 patients who received preoperative imatinib therapy for a median duration of 7 (2-12) months, 8 experienced a partial response, 3 had stable disease, and 1 had a complete response. Thirty and 11 patients underwent function-sparing conservative surgery and abdominoperineal resection, respectively. Tumor resections were mostly R0 and R1 in 35 patients. Tumor rupture occurred in 12 patients. Eleven patients received postoperative imatinib with a median follow-up of 59 (2.4-186) months. The median time to disease relapse was 36 (9.8-62) months. The 5-year overall survival rate was $86.5 \%$. Twenty patients developed local recurrence after surgery alone, two developed recurrence after resection combined with preoperative and/or postoperative imatinib, and eight developed metastases. In univariate analysis, the mitotic index $(\leq 5)$ and tumor size $(\leq 5 \mathrm{~cm})$ were associated with a significantly decreased risk of local relapse. Perioperative imatinib was associated with a significantly reduced risk of overall relapse and local relapse.
\end{abstract}

Conclusions: Perioperative imatinib therapy was associated with improved disease-free survival. Preoperative imatinib was effective. Tumor shrinkage has a clear benefit for local excision in terms of feasibility and function preservation. Given the complexity of rectal GISTs, referral of patients with this rare disease to expert centers to undergo a multidisciplinary approach is recommended.

\section{Background}

Gastrointestinal stromal tumors (GISTs) are rare but nonetheless represent the most common mesenchymal tumors of the gastrointestinal tract. The majority of GISTs arise in the stomach and small intestine [1], with an estimated annual incidence of 11 to 14.5 per million [2,3].

\footnotetext{
* Correspondence: thanh-khoa.huynh@mail.ap-hm.fr

'Service d'Oncologie Médicale, CHU Timone, AP-HM, Marseille, and

Aix-Marseille Université, Marseille, France

${ }^{15}$ Service d'Oncologie Médicale Adulte, CHU Timone, AP-HM, 264 rue Saint

Pierre, 13385 Marseille, France

Full list of author information is available at the end of the article
}

Rectal/pararectal GISTs are very rare and represent only 3 to $5 \%$ of all GISTs. Their incidence is estimated at 0.45 per million per year [4]. Few series of rectal GISTs have been reported in the literature, and the available reports are limited to a small number of cases [5-7].

Due to the rarity of rectal GISTs and the limited number of published studies, there is a paucity of data on how to optimally handle rectal GISTs. There is a tendency to treat rectal/pararectal GISTs as other GISTs, particularly as gastric GISTs. Management typically involves en bloc resection of the tumor, which avoids tumor rupture and

\section{Ciomed Central}


obtains clear margins; there is no need for lymphadenectomy because lymphatic metastases are exceedingly rare. Nevertheless, rectal/pararectal GISTs have a high risk of recurrence (local recurrence or metastasis), ranging from $55 \%$ for tumors of $>5 \mathrm{~cm}$ with a mitotic index (MI) of $\leq 5$ / $50 \mathrm{HPF}$ to $85 \%$ for tumors with an MI of $>5 / 50$ HPF regardless of size [8].

Surgery remains the only curative treatment for GISTs. However, because of the specific location of rectal GISTs, surgery is technically difficult and often extensive, possibly involving abdominoperineal or multivisceral resections, and raises the problem of sphincter preservation. Extensive surgery may result in considerable functional morbidity based on the tumor size, exact location of the tumor, and relationship of the tumor with vital pelvic structures (i.e., bladder, pelvic nerves, and anal sphincters). Therefore, the ability to shrink such a tumor in a safe and reliable manner is crucial to facilitate the performance of function-sparing surgical resection of disease.

Imatinib is a selective receptor tyrosine kinase inhibitor of the KIT and PDGFR- $\alpha$ receptor tyrosine kinases, which are pathophysiological drivers of GISTs. Imatinib is approved worldwide as a first-line systemic treatment for KIT-positive unresectable and/or metastatic GISTs and has revolutionized their treatment [9]. Since 2005, several case reports and small series regarding use of preoperative "neoadjuvant" imatinib treatment for rectal GISTs have been published [10-14], and some larger series have been more recently published $[15,16]$. These studies have shown that significant downstaging can be achieved with this targeted therapy, thus allowing conservative surgical procedures to be performed. More recently, imatinib treatment has been considered in the adjuvant setting to lower the risk of relapse [17]. Published reports of patients with rectal GISTs treated since the approval of imatinib, which has dramatically changed the treatment options and prognosis for GISTs, are rare $[15,16]$.

We conducted a 19-year retrospective analysis of rectal/pararectal GISTs with the aim of reviewing the clinicopathological characteristics, diagnostic and treatment approaches, choice of surgical procedure, perioperative use of imatinib, patterns of failure, and early and long-term results including overall survival and event-free survival.

\section{Methods}

We collected data of adult patients with rectal/pararectal GISTs treated from November 1991 to March 2011 in 12 French Sarcoma Group institutions and the Centre Hospitalier Universitaire Vaudois (CHUV) Lausanne. A standard data file was created to retrieve information on patient characteristics (gender, age at diagnosis, Eastern Cooperative Oncology Group [ECOG] performance status, and initial clinical symptoms), clinicopathological tumor characteristics, treatment approaches including surgical management and medical treatment (neoadjuvant and/or adjuvant imatinib), and patterns of failure (local recurrence or distant metastasis). Follow-up information was obtained during outpatient visits.

The diagnosis of GIST was confirmed by an experienced local pathologist using morphology and immunohistochemical staining for KIT (CD117) and CD34. Seven GISTs diagnosed as leiomyosarcoma before the year 2000 were reclassified as GISTs at the time of recurrence. Tumors were classified using standard risk assessment criteria using both the classification proposed by Fletcher (NIH consensus risk) [18], which is based on tumor size and number of mitoses, and the classification proposed by Miettinen [19], which is based on the MI, tumor size, and tumor site.

\section{Ethics statement}

This was a retrospective minimal-risk review, and all patients consented to the use of their standard clinical data. Our institutional review board exempts such minimal-risk survey studies from requiring institutional review board approval according to French laws. The board of directors of the French Sarcoma Group approved the study.

\section{Statistical analysis}

Continuous variables are expressed as median (range), and categorical variables are expressed as percentages. We retrospectively analyzed all prognostic factors, including patient characteristics (sex, age, ECOG performance status), tumor characteristics (tumor site in rectum, tumor size, KIT, CD34, MI/50 HPF, NIH categories, Miettinen categories, necrosis, histological subtype, and mutational status), surgical management (type of procedure, radical vs conservative surgery, margins [R0 vs R1 vs R2 or R0 vs R1-R2 or R0-R1 vs R2], tumor rupture, surgery-related complications), and medical treatment (imatinib treatment group vs non-imatinib treatment group). Fisher's exact test was used to compare percentages. Survival curves were plotted using the Kaplan-Meier method and compared with the log-rank test. Overall survival was calculated based on the interval from diagnosis to patient's death or last follow-up. Local relapse-free survival was defined as the interval between diagnosis and any subsequent occurrence of a tumor in the same location. Event-free survival was defined as the interval between diagnosis and local relapse and/or distant metastasis. All statistical tests were twosided, and the threshold for statistical significance was set at $\mathrm{p}=0.05$. Analyses were performed with SPSS software, version 17.0 (SPSS Inc., IL, USA). 


\section{Results}

Patient and disease characteristics

Patient and tumor characteristics are described in Table 1.

During the period from November 1991 to March 2011, a total of 41 adult patients with localized rectal/ pararectal GISTs were included in this review, including 4 patients reported in a separate therapeutic trial known as the French Sarcoma Group BFR 14 study [20]. The median age at diagnosis was 60 years (range, 33-82 years). The staging of the primary tumor included abdominopelvic computed tomography (CT) in 21 patients (51\%), pelvic magnetic resonance imaging (MRI) in 18 patients (44\%), endorectal ultrasonography in 23 patients (56\%), and positron emission tomography-CT in 6 patients $(15 \%)$.

The median tumor size was $62 \mathrm{~mm}$ (range, 6-130 $\mathrm{mm}$ ). GISTs were mostly located in the middle third (9 patients, $24 \%$ ) and lower third (22 patients, 50\%) of the rectum. Only seven GISTs (17\%) were located in pararectal spaces (presacral space, ischiorectal fossa, rectovaginal space, and rectoprostatic space). Histologically, the tumors were predominantly spindle-cell type $(\mathrm{n}=31,76 \%)$. Immunohistochemically, $83 \%$ of the tumors were KIT (CD117)-positive, and $78 \%$ were CD34-positive. The mutational status was determined in only 12 cases and revealed KIT exon 11 mutations in 10 cases.

\section{Treatment}

Treatment modalities (surgery and imatinib therapy) are presented in Table 2.

\section{Treatment strategy}

All patients underwent tumor resection. Twenty-five patients underwent surgery only. Imatinib was not given either because of the small tumor size or because it was not available at the time of diagnosis. A total of 16 patients underwent operations and received preoperative $(n=5)$, postoperative $(n=4)$, or preoperative and postoperative $(n=7)$ receptor tyrosine kinase inhibitor therapy with imatinib. Twenty-nine (70\%) patients underwent surgery as the initial treatment, but 12 were treated with imatinib preoperatively because of the tumor size.

\section{Surgery}

All patients underwent surgery. Different types of surgical procedures were performed. Local removal of the tumor was performed in 30 of 41 patients and involved anterior resection with coloanal or sus-anal anastomosis in $12(29 \%)$ patients, transanal/trans-sacral/transvaginal resection in 7 (17\%) patients, endoanal/endovaginal excision in $6(14.6 \%)$ patients, and unspecified resection in 5 (12\%) patients, resulting in $14 \mathrm{R} 0,10 \mathrm{R} 1$, and $4 \mathrm{R} 2$ resections of 30 conservative surgeries and 2 unspecified resections. Abdominoperineal resection was performed in 11 of 41 (27\%) patients, resulting in 8 of 11 R0, 3 of 11
R1, and no R2 resections. In proportion, sphincter-sparing surgery was performed in $61 \%$ of patients, and abdominoperineal resection was performed in $27 \%$ of patients. Abdominoperineal resection was more likely to result in negative margins than local surgery ( 8 of 11 vs 14 of 30 , respectively; $\mathrm{p}<0.05)$.

Seven patients (17\%) experienced complications related to surgery: infection $(n=4)$, occlusion $(n=1)$, and disunity of the coloanal anastomosis $(n=2)$. Complications were fatal in one patient who died of a small bowel fistula. Tumor rupture occurred during surgery in nine patients (22\%).

\section{Preoperative imatinib therapy}

Among the 41 patients, 12 (30\%) received preoperative imatinib at $400 \mathrm{mg}$ daily before surgical resection, with a median preoperative treatment period of 7 months (range, 2-12 months). All tumors except two were in the inferior third of the rectum. The tumor response was assessed every 2 to 3 months by CT and/or MRI. Of the 12 patients, 8 showed a partial response according to Response Evaluation Criteria in Solid Tumors (RECIST), 1 had a complete response, and 3 had stable disease or a minor response.

Two patients underwent abdominoperineal resection despite a partial response after imatinib therapy; all had negative margins and no postoperative complications. Ten patients underwent a sphincter-sparing surgery; all except one had negative margins (R0), and four of them had postoperative complications.

\section{Postoperative imatinib therapy}

According to their estimated risk of relapse, 11 (27\%) patients were treated with imatinib postoperatively at $400 \mathrm{mg} /$ day for a median duration of 7 months (range, 2-41 months). Seven after surgery performed after preoperative imatinib therapy and four after surgery only.

\section{Patient outcomes (Table 3) \\ Recurrence}

Local recurrence occurred in 20 (49\%) patients, including $18(72 \%)$ in the non-imatinib treatment group and only $2(16 \%)$ in the imatinib treatment group $(\mathrm{p}<0.001)$. The median follow-up duration in the imatinib treatment group was 39 months (range, 5-81 months), and that in the non-imatinib treatment group was 68 months (range, 2-186 months).

Among the 20 local recurrences, 6 (54.6\%) developed in the 11 patients who underwent abdominoperineal resection (exclusively in the non-imatinib treatment group), and 14 (46\%) developed among the 30 patients who underwent local resection ( 2 who received imatinib and 12 who did not receive imatinib). Furthermore, these local recurrences developed in 8 of 22 patients after R0 
Table 1 Patient and tumor characteristics

\begin{tabular}{|c|c|}
\hline Characteristics & $n=41$ \\
\hline \multicolumn{2}{|l|}{ Gender } \\
\hline Male & $29(71 \%)$ \\
\hline Female & $12(29 \%)$ \\
\hline \multicolumn{2}{|l|}{ Age (years) } \\
\hline Median (min-max) & $60(33-82)$ \\
\hline \multicolumn{2}{|l|}{ ECOG } \\
\hline $0 / 1$ & 16/15 (98\%) \\
\hline \multicolumn{2}{|l|}{ Symptoms-Clinical manifestations } \\
\hline Abdominal pain & $9(22 \%)$ \\
\hline Constipation & $4(10 \%)$ \\
\hline Rectal bleeding & $5(12 \%)$ \\
\hline Accidental discovery & $9(22 \%)$ \\
\hline $\begin{array}{l}\text { Others (genito urinary, pelvic } \\
\text { heaviness) }\end{array}$ & $6(15 \%)$ \\
\hline Unknown & $8(19 \%)$ \\
\hline \multicolumn{2}{|l|}{ Tumor characteristics } \\
\hline \multicolumn{2}{|l|}{ Tumor location } \\
\hline Rectum (Middle third/Lower third) & $9 / 22(24 / 50 \%)$ \\
\hline Pararectal space & $7(17 \%)$ \\
\hline Unspecified & $3(9 \%)$ \\
\hline \multicolumn{2}{|l|}{ Tumor size (mm) } \\
\hline median (min-max) & $62(6-130)$ \\
\hline \multicolumn{2}{|l|}{ Evaluated by: } \\
\hline Abdominopelvic CT Scan & $21(51 \%)$ \\
\hline MRI & $18(44 \%)$ \\
\hline Endosonography & $23(56 \%)$ \\
\hline Unknown & $6(14 \%)$ \\
\hline
\end{tabular}

Histology/Genotype/risk

CD117+ $34(83 \%)$

CD34+

Mitotic index

$\leq 5 / 50 \mathrm{HPF} \quad 11(27 \%)$

$>5 / 50 \mathrm{HPF} \quad 21(51 \%)$

Unknown

Mutation status (done on 12 cases)

KIT Exon 11 mutation in 10/12

KIT Exon 9 mutation in 1/12

KIT Exon 17 mutation in 1/12

None PDGFRA mutation

\section{NIH risk categories}

$\begin{array}{lc}\text { Very low risk } & 3(7 \%) \\ \text { Low risk } & 3(7 \%) \\ \text { Intermediate risk } & 6(14 \%) \\ \text { High risk } & 18(42 \%)\end{array}$

Table 1 Patient and tumor characteristics (Continued)

\begin{tabular}{lc}
\hline Miettinen risk categories & \\
None risk & $3(7 \%)$ \\
Low risk & $4(10 \%)$ \\
High risk & $23(56 \%)$ \\
Insufficient data (unclassified) & $11(26 \%)$ \\
\hline
\end{tabular}

resection, 9 of 13 patients after R1 resection, and 3 of 4 patients after R2 resection. Eight of 41 patients (20\%) developed distant metastases: $6(24 \%)$ in the non-imatinib treatment group and $2(13 \%)$ in the imatinib treatment group $(\mathrm{p}=0.448)$.

\section{Survival analysis and prognostic factors}

The median overall follow-up period was 59 months (range, 2.4-186 months). Nine patients died during the follow-up period. The 3 -and 5-year overall survival rates of patients with localized rectal/pararectal GISTs were 97.5 and $86.5 \%$, respectively (Figure 1A). The median event-free survival period was 36 months (range, 9.862 months), with 3-and 5-year event-free survival rates of 53.9 and $34.6 \%$, respectively (Figure 1B). The median local relapse-free survival period was 58 months (range, 29-86 months), with 3-and 5-year local relapse-free survival rates of 60.2 and $42.1 \%$, respectively (Figure 1C).

In the univariate analysis, only tumor size $(\mathrm{p}=0.004)$ (Figure 2A), mitotic count $(\mathrm{p}=0.048)$ (Figure $2 \mathrm{~B}), \mathrm{NIH}$ risk $(\mathrm{p}=0.023)$ (Figure $2 \mathrm{C})$, and imatinib treatment $(\mathrm{p}=$ 0.006) (Figure 2D) were predictive of local relapse.

A tumor size of larger than $5 \mathrm{~cm}$ and an MI of higher than 5/50 HPF increased the risk of local recurrence, as expected with these known prognostic factors [16]. A low MI $(\leq 5 / 50 \mathrm{HPF})(\mathrm{p}=0.008)$ and imatinib treatment $(\mathrm{p}=0.011)$ were associated with a significantly lower risk of overall relapse (local recurrence and distant metastasis), but had no impact on overall survival. Sex, age, NIH risk, Miettinen risk categories, tumor margins, tumor rupture, and tumor local control had no influence on event-free survival or overall survival in the univariate analysis. In the multivariate analysis, we could not demonstrate whether tumor size, MI, or NIH risk were independent factors.

Preoperative and/or postoperative imatinib treatment significantly reduced the risk of overall relapse $(p=0.011)$ and local relapse $(\mathrm{p}=0.006)$ (Figure 2D), with a significant impact on disease-free survival but no demonstrable impact on overall survival.

\section{Discussion}

GISTs are unusual tumors overall, while rectal GISTs are a particularly rare subtype, representing less than $5 \%$ of all GISTs. Few data are available on the presentation, 
Table 2 Results of treatment

\begin{tabular}{|c|c|}
\hline Characteristic & $\begin{array}{c}n=41 \text { localized } \\
\text { tumors }\end{array}$ \\
\hline \multicolumn{2}{|l|}{ Quality of surgery } \\
\hline \multicolumn{2}{|l|}{ Resection } \\
\hline RO & $22(53 \%)$ \\
\hline R1 & $13(32 \%)$ \\
\hline R2 & $4(10 \%)$ \\
\hline \multicolumn{2}{|l|}{ Tumor rupture } \\
\hline Yes & $9(22 \%)$ \\
\hline No & $29(70 \%)$ \\
\hline Primary surgery/Post imatinib surgery & $29 / 12$ \\
\hline Post-operative complications & $7(17 \%)$ \\
\hline Anastomotic leakage of coloanal anastomosis & 2 \\
\hline Small bowel fistula with death & 1 \\
\hline Pelvic peritonitis & 1 \\
\hline Pararectal abscess and anorectal fistula & 1 \\
\hline Occlusion & 1 \\
\hline Fever & 1 \\
\hline Imatinib (IM) therapy group (400 mg/day) & $16(37.5 \%)$ \\
\hline Preoperative IM & $12(30 \%)$ \\
\hline No neoadjuvant IM group (immediate surgery) & $29(70 \%)$ \\
\hline Post operative IM & $11(27 \%)$ \\
\hline from « neoadjuvant group » & 7 \\
\hline from « immediate surgery group» & 4 \\
\hline Median duration preoperative IM (month) & $7(2-12)$ \\
\hline Median duration post operative IM (month) & $7(2-41)$ \\
\hline Efficacy of preoperative IM therapy & 12 \\
\hline Partial response & 8 \\
\hline Complete response & 1 \\
\hline Stable disease/minor response & 3 \\
\hline
\end{tabular}

management, and survival of patients with primary rectal GISTs.

Our retrospective study of 41 localized rectal GISTs over the last 20 years is, to our knowledge, one of the largest series currently reported in the literature. The two most recent and large series on primary rectal GISTs reported 39 cases from 2 referral departments for sarcomas/GIST surgeries over the last 8 years [16] and 32 cases from 6 surgical oncology and medical oncology departments in the Netherlands over the last 21 years [15].

Patient demographics showed a male predominance (71\%), as already suggested in other series on primary rectal GISTs $[8,15,16,21]$, although most large epidemiological studies of GISTs overall have shown a well-balanced sex ratio with respect to incidence $[2,22]$. The presentation and symptoms of these 41 rectal GISTs were not different
Table 3 Outcome

\begin{tabular}{|c|c|}
\hline Characteristics & $\begin{array}{c}\mathrm{n}= \\
\text { tumors }\end{array}$ \\
\hline \multicolumn{2}{|l|}{ Follow-up (month) } \\
\hline Median & 59 \\
\hline $\min$ & 2.4 \\
\hline $\max$ & 186 \\
\hline \multicolumn{2}{|l|}{ Prognosis } \\
\hline Death & 9 \\
\hline Local relapse & $20(49 \%)$ \\
\hline Metastases & 8 \\
\hline \multicolumn{2}{|l|}{ Local relapse } \\
\hline In the « non imatinib treatment group » & $18(72 \%)$ \\
\hline In the « imatinib treatment group » & $2(16 \%)$ \\
\hline \multicolumn{2}{|l|}{$\begin{array}{l}6 / 11 \text { patients }(54.5 \%) \text { who underwent } \\
\text { abdominoperineal resection (exclusively } \\
\text { in « non IM group) }\end{array}$} \\
\hline \multicolumn{2}{|l|}{ Metastases } \\
\hline In the « non imatinib treatment group» & 6 \\
\hline In the « imatinib treatment group» & 2 \\
\hline Local relapse-free survival at 3 years & $60.2 \%[\mathrm{Cl} 95 \%=45.8-79.1]$ \\
\hline Local relapse-free survival at 5 years & $42.1 \%[\mathrm{Cl} 95 \%=26.8-66.3]$ \\
\hline DFS at 3 years & $53.9 \%[C 195 \%=39.3-73.8 \%]$ \\
\hline DFS at 5 years & $34.6 \%[C 195 \%=19.9-60.2 \%]$ \\
\hline OS at 3 years & $97.5 \%[C 195 \%=92.8-100 \%]$ \\
\hline OS at 5 years & $86.5 \%[C 195 \%=74.9-100 \%]$ \\
\hline
\end{tabular}

from those commonly found for other rectal tumors despite the fact that the clinical presentation was sometimes misleading, with rectal GISTs causing genitourinary and gynecological symptoms because of compression or invasion of adjacent pelvic organs. Therefore, we agree with other authors $[6,16,23]$ that pelvic/rectal GISTs should be integrated into the framework of differential diagnoses along with other submucosal rectal and pelvic tumors.

The mutational status was only determined in a subset of 12 patients, in whom KIT exon 11 mutations were demonstrated in 10, KIT exon 9 mutation in 1 , and no mutation in 1 . In this retrospective study, tumor mutational testing for the oncogenic KIT and/or PDGFRA genes was able to be performed in only 12 of 41 (29\%) of these rare patients with rectal GISTs. Given the known challenges described below, obtaining evaluable tissues from patients identified over more than a decade is simply not feasible. In three patients who underwent resection of the primary tumor between 2000 and 2008, paraffinembedded blocks were collected, but the quality of tumor material was insufficient to perform mutational testing because of technical challenges associated with these older blocks and the tissue fixation procedure. For nine other 


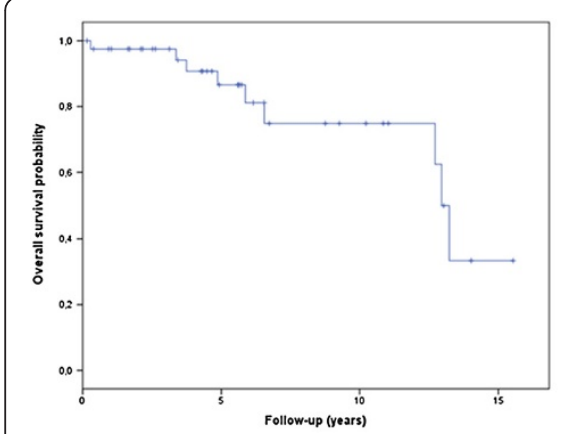

A: Overall survival

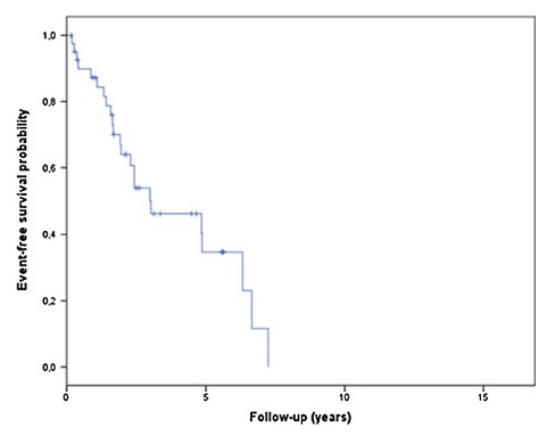

B: Disease-free survival

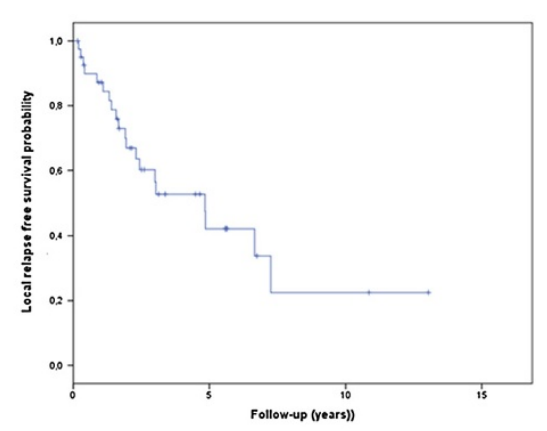

C: Local relapse-free survival

Figure 1 Survival curves.

patients, resection of primary GISTs was performed before 1999, and the quality of the tissue specimen from the primary tumor was insufficient to determine the mutational status. Thus, despite our best efforts, retrospective mutational examination of any additional patients in our series is unfortunately not possible. However, our team believes that the information provided in this series is useful because tumor mutational testing is routinely performed in only a minority (approximately $5 \%$ ) of GISTs worldwide. Nevertheless, the mutation

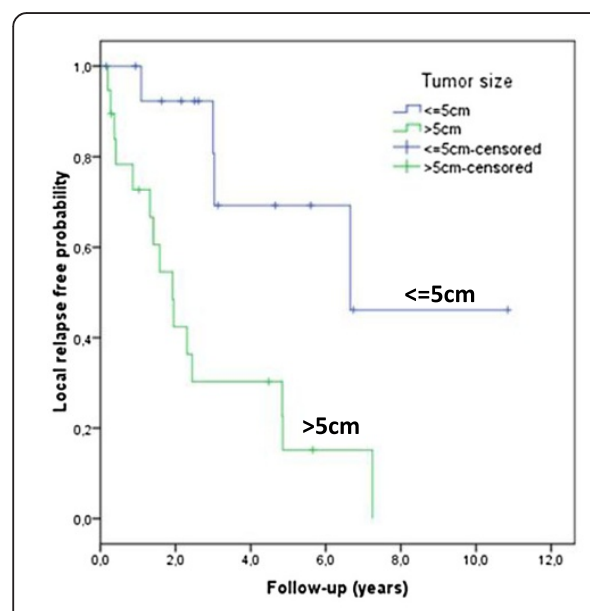

A: Tumor size

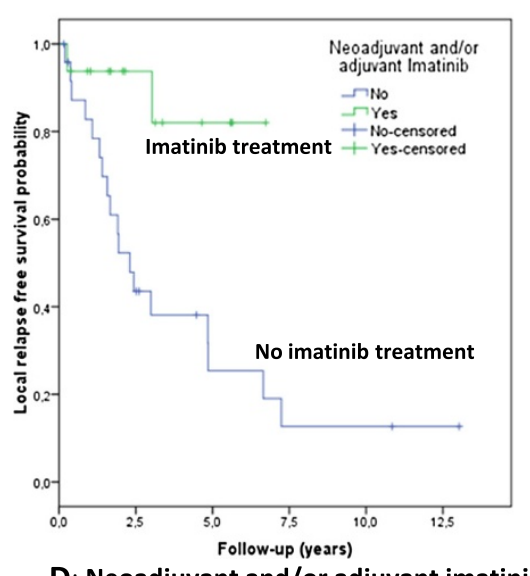

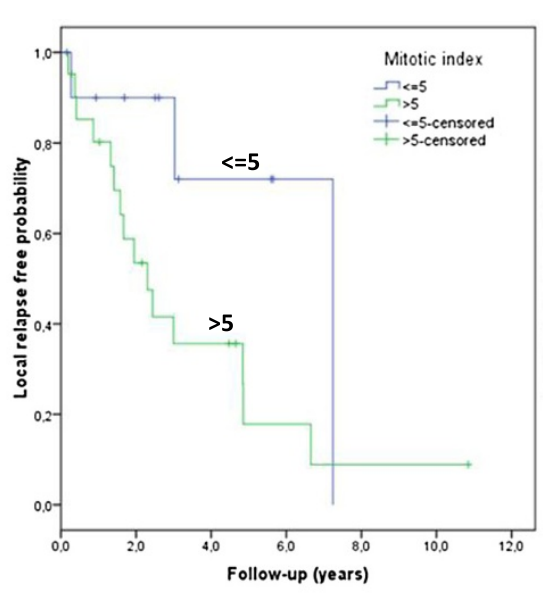

B: Mitotic index

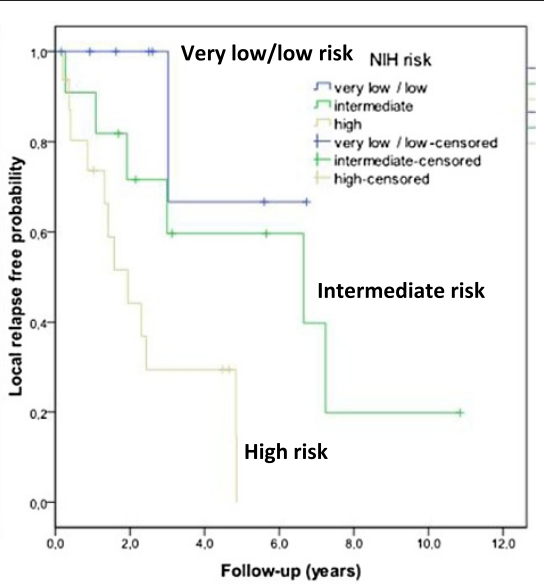

C: NIH risk

D: Neoadjuvant and/or adjuvant imatinib

Figure 2 Factor associated with local relapsed-free survival. 
frequency in rectal GISTs has not been specifically investigated $[15,16]$ except in Miettinen's study [8], which found mutations in 18 of 29 (62\%) of the cases evaluated, with a predominance of KIT exon 11 mutations, a lack of KIT exon 13 mutations, and only one KIT exon 9 mutation.

In our study, $56 \%$ of the patients were classified in the high-risk group according to the Miettinen classification [19], and 56\% of patients relapsed after surgical resection of primary localized GISTs with disease-free survival rates of 53.9 and $34.6 \%$ at 3 and 5 years, respectively. This confirms the more aggressive behavior of rectal GISTs. These data also corroborated the results of Mussi et al. [21], Tsai et al. [24], and Miettinen et al. [8], who showed that the majority of rectal GISTs are large, demonstrate high-risk malignant behavior, and have a tendency to recur and metastasize. Furthermore, in three Korean studies, colorectal GISTs occurred predominantly in the rectum and tended to be classified as high-risk, which was the most important risk factor for recurrence [25-27].

The cornerstone in treatment for patients with localized GISTs is complete surgical resection with en bloc tumor removal and clear margins, avoiding tumor rupture. In our series, the relatively high rate of tumor rupture during surgical resection might be explained by several factors in this rare subset of patients with GIST. In particular, this is a particularly challenging anatomical location for primary GISTs, and the risk of rupture definitely seems higher than that in many other sites. In five of our patients, the large size of the primary tumor $(8-10 \mathrm{~cm})$ in this constrained anatomic space likely contributed to the risk of rupture. In another three patients, the surgical resection was performed by endoanal or transvaginal enucleation with resultant fragmentation of the tumor. Conversely, rectal GISTs are often large tumors. Therefore, they are a challenge for surgeons because of the confined pelvic space (anatomical location close to the anal sphincters, pelvic nerves, and bladder) and the fact that they are often adherent to the pelvic floor. As a consequence, rectal GISTs might require extensive surgery (e.g., abdominoperineal or multivisceral resection) to achieve complete surgical resection. Nevertheless, various conservative surgical procedures and approaches may be considered for rectal GISTs, including local excision, anterior resection, trans-sacral/ anal/vaginal approaches, and laparoscopic approaches [28-30]. The choice of the procedure mainly depends on the tumor size and location in relation to the anorectal margin. In our series, only 11 (27\%) patients underwent abdominoperineal resection, and 30 patients were eligible for conservative surgery with various surgical procedures.

Nevertheless, resections with clear margins (R0 resections) were more common with abdominoperineal procedures than with conservative surgery ( $8 / 11$ and $14 /$ 30 , respectively), but tumor recurrence occurred similarly in both groups of patients: in 6 of 11 patients (54\%) after abdominoperineal surgery and in 11 of 30 patients (46.6\%) after conservative surgery.

Because of the rarity of this disease, no prospective studies have compared radical surgery versus conservative surgery or local tumor excision, and only such a study could elucidate the value of this radical surgery. Khalifa et al. [31] reported that there was no difference in survival rates between local resection and abdominoperineal resection in patients with rectal sarcoma. We believe that local resection should be performed if microscopically clear margins can be safely achieved.

Preoperative imatinib therapy was administered to 12 (30\%) of the patients in this series because of large GISTs, difficulty of complete tumor removal, and preservation of the anal sphincters. In all cases, it enabled a modification in tumor size and/or density. It also permitted the performance of conservative surgery in 8 of 12 patients ( 6 of these 8 tumors were located in the lower third of the rectum). Thus, this treatment was feasible, safe, and effective. Since 2005, several case reports or small series regarding the use of preoperative imatinib treatment for rectal GISTs have been published [10-13,32-35]. All concluded that preoperative imatinib therapy has an important role in downsizing large rectal GISTs and in reducing the mitotic activity. Because these tumors are in the vicinity of pelvic structures (i.e., bladder, major pelvic nerves, and anal sphincters) and given that radical surgery may lead to considerable morbidity, downstaging might be beneficial in this situation, allowing function-sparing procedures and less invasive surgery while potentially improving tumor resectability. Preoperative treatment is thus a reasonable option for patients with locally advanced rectal GISTs that require abdominoperineal or multivisceral resection for complete tumor removal.

Controversy remains regarding the optimal duration of preoperative therapy. Our patients received preoperative imatinib for a median duration of 7 months (range, 2-10 months). In the EORTC phase III trial, the median time to best response was 4 months, but some responses were documented later [36]. Similar observations have been made in case reports of preoperative imatinib in localized diseases [37]. Therefore, it would be reasonable to plan a final surgery within 6 to 12 months of imatinib onset [34].

Interestingly in our series, 18 patients $(72 \%)$ in the nonimatinib group and only $2(16 \%)$ in the imatinib group developed local recurrence. We showed that preoperative and/or postoperative imatinib significantly reduced the risk of not only local recurrence $(\mathrm{p}=0.006)$, but also overall relapse $(\mathrm{p}=0.011)$, and significantly improved the disease-free survival with no impact on overall 
survival. These results are in accordance with those from Andtbacka et al. [38] on 16 locally advanced GISTs from several locations treated with preoperative imatinib and those from Tielen et al. on 32 rectal GISTs, 22 treated with preoperative imatinib and 10 with surgery only [15].

\section{Conclusions}

Based on these data, we suggest that a therapeutic strategy combining surgery with preoperative imatinib therapy should be systematically considered for patients with rectal GISTs, specifically for patients with larger tumors, marginally resectable tumors, or tumors close to the anal sphincters because imatinib may potentially increase the proportion of patients able to undergo conservative surgery rather than the more morbid abdominoperineal resection. Furthermore, according to the results of the ACOSOG Z9001 study and two recent Scandinavian studies $[17,39]$, the indication to continue imatinib in the postoperative setting for a duration of at least 1 year has been established in patients with high-risk GISTs, when incomplete surgical resection has occurred, or when tumor rupture has occurred. This should be systematically discussed with patients according to the risk of disease recurrence per the standard risk assessment criteria.

Due to the rarity of these tumors, these decisions require the multidisciplinary expertise of surgeons, medical oncologists, radiologists, and gastroenterologists in expert centers. Referral of patients with this rare disease to expert centers is recommended.

\section{Competing interests}

The authors declare that they have no competing interests.

\section{Authors' contributions}

$\mathrm{TKH}+\mathrm{FD}$ have made substantial contributions to conception and design. JM participated in the design of the study and performed the statistical analysis. All the authors have been involved in drafting the manuscript and revising it critically for important intellectual content. All the authors have given final approval of the version to be published.

\section{Acknowledgements}

The authors wish to thank the patients, the patients' families, and the surgeons. This study was supported by a NetSarc grant from the French INCa, RREPS grant from the French INCa, Eurosarc (HEALTH-F2-2011-278742), and Conticanet (FP6-018806)

\footnotetext{
Author details

${ }^{1}$ Service d'Oncologie Médicale, CHU Timone, AP-HM, Marseille, and Aix-Marseille Université, Marseille, France. ${ }^{2}$ Service de Chirurgie, Centre Léon Bérard, Lyon, France. ${ }^{3}$ Service d'Oncologie Médicale, Centre Léon Bérard, Lyon, France. ${ }^{4}$ Service d'Oncologie Digestive, CHU Robert Debré, Reims, France. ${ }^{5}$ Service de Chirurgie, CHU Robert Debré, Reims, France. ${ }^{6}$ Service d’Oncologie Médicale, Centre Oscar Lambret, Lille, France. ${ }^{7}$ Service d'Oncologie Médicale, Hôpital St Antoine, Assistance Publique-Hôpitaux de Paris and Université Pierre \& Marie Curie (UPMC), Paris, France. ${ }^{8}$ Service de Santé Publique et d'Information Médicale, Unité de Biostatistique, CHU Timone, APHM, Marseille, and Aix-Marseille Université, Marseille, France. ${ }^{9}$ Service d'Oncologie Médicale, CLCC, Institut de Cancérologie Lucien Neuwirth, Saint-Etienne, France. ${ }^{10}$ Centre Pluridisciplinaire d'Oncologie, CHUV Lausanne, Lausanne, Suisse. ${ }^{11}$ Service d'Oncologie médicale, Centre René Gauduchau, Nantes, France. ${ }^{12}$ Service d'Oncologie Médicale, Centre Alexis Vautrin, Vandoeuvre les, Nancy, France. ${ }^{13}$ Service d'Oncologie Médicale,
}

Centre George François Leclerc, Dijon, France. ${ }^{14}$ Service d'Oncologie Médicale, Centre Valdorelle, Montpellier, France. ${ }^{15}$ Service d'Oncologie Médicale Adulte, CHU Timone, AP-HM, 264 rue Saint Pierre, 13385 Marseille, France.

Received: 8 December 2012 Accepted: 21 February 2014 Published: 5 March 2014

\section{References}

1. Mazur MT, Clark MB: Gastric stromal tumors: reapparaisal of histogenesis. Am J Surg Pathol 1983, 7:507-519.

2. Tryggvason G, Gislason HG, Magnusson M, Jónasson JG: Gastrointestinal Stromal tumors in Iceland, 1990-2003: the Iceland Gist study, a population based incidence and patologic risk stratification study. Int J Cancer 2005, 117:289-293.

3. Nilsson B, Bümming P, Meis-Kindblom JM, Odén A, Dortok A, Gustavsson B, Sablinska K, Kindblom LG: Gastrointestinal stromal tumors: the incidence, prevalence, clinical course, and prognostication in the preimatinib mesylate era: a population-based Study in Western Sweden. Cancer 2005, 103:821-829.

4. Conlon KC, Casper ES, Brennan MF: Primary gastrointestinal sarcomas: analysis of pronostic variables. Ann Surg Oncol 1995, 2:26-31.

5. Tworek JA, Goldblum JR, Weiss SW, Greenson JK, Appelman HD: Stromal tumors of the anorectum: a clinicopathologic study of 22 cases. Am J Surg Pathol 1999, 23:946-954.

6. Baik SH, Kim NK, Lee CH, Lee KY, Sohn SK, Cho CH, Kim H, Pyo HR, Rha SY, Chung HC: Gastrointestinal stromal tumor of the rectum: an analysis of seven cases. Surg Today 2007, 37:455-459.

7. Li JC, Ng SS, Lo AW, Lee JF, Yiu RY, Leung KL: Outcome of radical excision of anorectal gastrointestinal stromal tumors in Hong Kong Chinese patients. Indian J Gastroenterol 2007, 26:33-35.

8. Miettinen M, Furlong M, Sarlomo-Rikala M, Burke A, Sobin LH, Lasota J: Gastrointestinal stromal tumors intramural leïmyomas, and leïomyosarcomas in the rectum and anus: a clinicopathologic, immunohistochemical, and molecular genetic study of 144 cases. Am J Surg Pathol 2001, 25:1121-1123.

9. Demetri GD, Von Mehren M, Blanke CD, Van den Abbeele AD, Eisenberg $B$, Roberts PJ, Heinrich MC, Tuveson DA, Singer S, Janicek M, Fletcher JA, Silverman SG, Silberman SL, Capdeville R, Kiese B, Peng B, Dimitrijevic S, Druker BJ, Corless C, Fletcher CD, Joensuu H: Efficacy and safety of imatinib (STI 571) in advanced gastrointestinal stromal tumors. N Engl J Med 2002, 347:472-480.

10. Lo SS, Papachistou Gl, Finkelstein SD, Conroy WP, Schraut WH, Ramanathan RK: Neoadjuvant imatinib in gastrointestinal stromal tumor of the rectum: report of a case. Dis Colon Rectum 2005, 48:1316-1319.

11. Shah JN, Sun W, Seethala RR, Livolsi VA, Fry RD, Ginsberg GG: Neoadjuvant therapy with imatinib mesylate for locally advanced $\mathrm{Gl}$ stromal tumor. Gastrointest Endosc 2005, 61:625-627.

12. Ebihara Y, Okushiba S, Kawarada Y, Kitashiro S, Katoh H, Kondo S: Neoadjuvant imatinib in a gastrointestinal stromal tumor of the rectum: report of a case. Surg Today 2008, 38:174-177.

13. Santos Fernandes G, de Castro Cotti GC, Feitas D, Cutait R, Hoff PM: Downstaging of rectal gastrointestinal stromal tumor by neoadjuvant imatinib therapy allowing for a conservative surgical approach. Clinics 2009, 64:819-821.

14. Wassenberg N, Nunoo-Mensah JW, Beart RW Jr, Ker TS: Is there a role for neoadjuvant treatment with Gleevec for large rectal gastrointestinal stromal tumors? Int J Colorectal Dis 2007, 22:981-982.

15. Tielen $R$, Verhoef $C$, van Coevorden F, Reyners AK, van der Graaf WT, Bonenkamp JJ, van Etten B, de Wilt JH: Surgical management of rectal gastrointestinal stromal tumours. J Surg Oncol 2012. doi:10.1002/jso.23223.

16. Jakob J, Mussi C, Ronellenfitsch U, Wardelmann E, Negri T, Gronchi A, Hohenberger P: Gastrointestinal stromal tumor of the rectum: results of surgical and multomodality therapy in the era of Imatinib. Ann Surg Oncol 2013, 20:586. online september 12.

17. Dematteo RP, Ballman KV, Antonescu CR, Maki RG, Pisters PW, Demetri GD, Blackstein ME, Blanke CD, von Mehren M, Brennan MF, Patel S, McCarter MD, Polikoff JA, Tan BR, Owzar K, American College of Surgeons Oncology Group (ACOSOG) Intergroup Adjuvant GIST Study Team: Adjuvant imatinib mesylate after resection of localised, primary gastrointestinal stromal 
tumor: a randomised, double-blind, placebo-controlled trial. Lancet 2009, 373:1097-1104.

18. Fletcher CD, Bermann JJ, Corless C, Gorstein F, Lasota J, Longley BJ, Miettinen M, O'Leary TJ, Remotti H, Rubin BP, Shmookler B, Sobin LH, Weiss SW: Diagnosis of gastrointestinal stromal tumors: a consensus approach. Hum Pathol 2002, 33:459-465.

19. Miettinen M, Lasota J: Gastrointestinal stromal tumors: pathology and prognosis at different sites. Semin Diagn Pathol 2006, 23:70-83.

20. Blay JY, Le Cesne A, Ray-Coquard I, Bui B, Duffaud F, Delbaldo C, Adenis A, Viens P, Rios M, Bompas E, Cupissol D, Guillemet C, Kerbrat P, Fayette J: Prospective multicentric randomized phase III study of imatinib in patients with advanced gastrointestinal stromal tumors comparing interruption versus continuation of treatment beyond 1 year: the French Sarcoma Group. J Clin Oncol 2007, 25(9):1107-1113.

21. Mussi C, Jakob J, Wardelmann E, Reichardt P, Casali PG, Fiore M, Collini P, Gronchi A, Hohenberger P: Gastrointestinal stromal tumor of rectum and rectovaginal space: a retrospective review. ASCO Ann Meet 2008. Abstract $n^{\circ} 10560$.

22. Goettsh G, Bos SD, Breekveldt-Potsma N, Casparie M, Herings RM, Hogendoorn PC: Incidence of gastrointestinal stromal tumors is underestimated: results of a nationwide study. Eur J Cancer 2005, 41:2868-2872

23. Yoon KJ, Kim NK, Lee KY, Min BS, Hur H, Kang J, Lee S: Efficacy of imatinib mesylate neoadjuvant treatment for a locally advanced rectal gastrointestinal stromal tumor. J Korean Soc Coloproctol 2011, 27:147-152.

24. Tsai MC, Lin JW, Lin SE, Chen HH, Lee CM, Hu TH: Prognostic analysis of rectal stromal tumors by reference of National Institute of Health risk categories and immunohistochemical studies. Dis Colon Rectum 2008, 51:1535-1543

25. Park KC, Kim HC, Park IJ, Yu CS, Kim JS, Kim JC: Clinicopathologic and immunohistochemical features of gastrointestinal stromal tumors (GISTs) in the colon \& rectum. J Korean Soc Coloproctol 2004, 20:371-377.

26. Choi SH, Kim SJ, Choi YJ, Min BS, Kim JS, Baik SH, Kim NK, Kang JG: Clinicopathologic analysis of gastrointestinal stromal tumors of the colon and rectum. J Korean Soc Coloproctol 2009, 25:323-333.

27. Paek OJ, Kim YB, Oh SY, Suh KW: Gastrointestinal stromal tumors of the colon and rectum. J Korean Soc Coloproctol 2009, 25:318-322.

28. Gervaz P, Huber O, Bucher P, Sappino P, Morel P: Trans-sacral approach for gastrointestinal stromal tumor of the lower rectum: old procedure for a new disease. Colorectal Dis 2008, 10:951-952.

29. Hellan M, Maker VK: Transvaginal excision of a large rectal stromal tumor: an alternative. Am J Surg 2006, 191:121-123.

30. Nakamura T, Ihara A, Mitomi H, Kokuba Y, Sato T, Ozawa H, Hatade K, Onozato W, Watanabe M: Gastrointestinal stromal tumor of the rectum resected by laparoscopic surgery: report of case. Surg Today 2007, 37:1004-1008

31. Khalifa AA, Bong WL, Rao VK, Williams MJ: Leïomyosarcoma of the rectum. Dis Colon Rectum 1986, 29:427-432.

32. Wang JP, Wang T, Huang MJ, Wang L, Kang L, Wu XJ: The role of neoadjuvant imatinib mesylate therapy in sphincter-preserving procedures for anorectal gastrointestinal stromal tumour. Am J Clin Oncol 2011, 34:314-316.

33. Machlenkin S, Pinsk I, Tulchinsky H, Ziv Y, Sayfan J, Duek D, Rabau M, Walfisch S: The effect of neoadjuvant Imatinib therapy on outcome and survival after rectal gastrointestinal stromal tumour. Colorectal Dis 2011, 13:110-115.

34. Fiore M, Palassani E, Fumagalli E, Pilotti S, Tamborini E, Stacchiotti S, Pennacchioli E, Casali PG, Gronchi A: Preoperative imatinib mesylate for unresectable or locally advanced primary gastrointestinal stromal tumors (GIST). Eur J Surg Oncol 2009, 35:739-745.

35. Eisenberg BL, Harris J, Blanke CD, Demetri GD, Heinrich MC, Watson JC, Hoffman JP, Okuno S, Kane JM, von Mehren M: Phase II trial neoadjuvant/ adjuvant imatinib mesylate (IM) for advanced primary and metastatic recurrent operable gastrointestinal stromal tumor (GIST): early results of RTOG 0132/ACRIN 6665. J Surg Oncol 2009, 99:42-47.

36. Werweij J, Casali PG, Zalcberg J, LeCesne A, Reichardt P, Blay JY, Issels R, van Oosterom A, Hogendoorn PC, Van Glabbeke M, Bertulli R, Judson I: Progression-free survival in gastrointestinal stromal tumours with high-dose imatinib: randomised trial. Lancet 2004, 364:1127-1134.

37. Haller F, Detken S, Schulten HJ, Happel N, Gunawan B, Kuhlgatz J, Füzesi L. Surgical management after neoadjuvant imatinib therapy in gastrointestinal stromal tumours (GISTs) with respect to imatinib resistance caused by secondary KIT mutations. Ann Surg Oncol 2007 14:526-532.

38. Andbacka RH, Ng CS, Scaife CL, Cormier JN, Hunt KK, Pisters PW, Pollock RE, Benjamin RS, Burgess MA, Chen LL, Trent J, Patel SR, Raymond K, Feig BW: Surgical resection of gastrointestinal stromal tumors after treatment of imatinib. Ann Surg Oncol 2007, 14:14-24.

39. Joensuu $H$, Eriksson M, Hatrmann J, Hartmann JT, Pink D, Schütte J, Ramadori G, Hohenberger P, Duyster J, Al-Batran SE, Schlemmer M, Bauer S, Wardelmann E, Sarlomo-Rikala M, Nilsson B, Sihto H, Monge OR, Bono P, Kallio R, Vehtari $A$, Leinonen $M$, Alvegård $T$, Reichardt $P$ : One versus three years of adjuvant imatinib for operable gastrointestinal stromal tumor: a randomized trial. JAMA 2012, 307:1265-1272.

doi:10.1186/1471-2407-14-156

Cite this article as: Huynh et al:: Primary localized rectal/pararectal gastrointestinal stromal tumors: results of surgical and multimodal therapy from the French Sarcoma group. BMC Cancer 2014 14:156.

\section{Submit your next manuscript to BioMed Central and take full advantage of:}

- Convenient online submission

- Thorough peer review

- No space constraints or color figure charges

- Immediate publication on acceptance

- Inclusion in PubMed, CAS, Scopus and Google Scholar

- Research which is freely available for redistribution 